\title{
NUMERICAL STUDY AND ANALYSIS OF GAS TURBINE BLADES
}

\author{
NAWFEL M. BAQER, HAYDER H. KHALEEL \& NOOR H. DHAHER
}

Engineering Technical College / Najaf, Al-Furat Al-Awsat Technical University Al Najaf, Iraq

Gas turbine has great importance in the modern engineering applications, and it is the main element in the process of electric power generation. This paper presents a numerical analysis for gas turbine rotor blades to understand the behavior of gas turbine blades under the loads. The simulation was achieved by using solidworks 2018 and the numerical analysis by using ANSYS 15. Two materials were chosen to manufacture the gas turbine, which were Aluminum Alloy and Titanium Alloy under various values of load (5000,10000,15000)N to get many parameters such stress, total deformation, strain and shear stress. The results showed that by increasing the loads, all the values of obtained parameters were increased and it could be concluded that titanium alloy withstand the load more the aluminum alloy, and therefore it is recommended to use titanium alloy in manufacturing the gas turbine blades.

KEYWORDS: Gas Turbine, Solid Works, ANSYS 15, Aluminum Alloy \& Titanium Alloy
\end{abstract}

Received: Mar 28, 2019; Accepted: Apr 18, 2019; Published: May 20, 2019; Paper Id.: IJMPERDJUN2019104

\section{INTRODUCTION}

The gas turbine can be defined as a power plant to extract a large amount of mechanical power from the working fluid, with maximum efficiency. Gas turbine has a great role in the electric power generation, and by increasing the demand for power, the thermal efficiency of gas turbine and output power will be increased. A gas turbine is an engine that uses air as the working fluid and the fuel is continuously burnt with compressed air to produce a fast hot moving gas. Blades of gas turbine are the most important components, because they are subjected to high centrifugal tangential and axial forces during extracting energy from the high temperature and high pressure gases[1].

S. Gowreesh et.al [2] analyzed the design of the first stage rotor blade of a two stage gas turbine blade using by using finite elements analyzer software ANSYS. The evaluation of temperature field in the rotor blade was done and applied boundary conditions using this software model. The static loads and temperature had effect on the gas turbine blades.

Theju $\mathbf{V}$ et.al [3] investigated the effect of temperature and induced stresses on jet engines turbine blade for two various materials titanium T-6 and inconel -718. It was observed that the titanium had a smaller value of deformation and lower strength. It was noticed that theInconel-718 has better thermal properties and higher strength compared with the titanium. Brahmaiah \& Kumar [4] studied four various models of gas turbine blades with and without holes and analyzed the effect of changing the number of holes (5,9 and 13) on the blades behaviour. The structural analysis and steady state thermal were achieved by using ANSYS. The results of temperature distribution and transfer rate showed that the blade with 13 holes was considered as optimum. They had used two materials chromium steel and Inconel- 718 for their research, it was observed that the Inconel 
was with induced stresses, lesser than the chromium steel with a better thermal characteristics. Steady state thermal analysis of gas turbine rotor blade in ANSYS 14.5 has been investigated by Laihtwe et.al [5]. The results demonstrate that the values of total thermal heat fluxes for three different materials (copper, titanium and nickel)were depend upon the convection heat transfer coefficient and thermal conductivity of the material. It is observed that the titanium material could bear the temperature up to $2018.6^{\circ} \mathrm{K}$ with least value of the total thermal heat flux. For the results of steady state thermal analysis, the titanium material was better when compared with the two other materials. Boyaraju et.al [6] Analyzed a gas turbine, which is a mechanical element designed to extracts thermal energy from pressurized steam, and converts it into useful work such as mechanical shaft power. In order to design a solid model, CATIA V5 was used. The structural and thermal analysis was completed to the different models with two materials AL 2024 and T6.The results show that the lowest temperature is recorded in model with T6by comparing the models, and the lowest fluxes are recorded in model with AL 2024.Krishnakanth et al. [7] conducted study on structural and thermal analysis of gas turbine rotor blade using solid95 element; the study was done on three different materials Inconel 625, Haste alloy X and N-155. It was observed that the minimum elongation and temperature deviations occurred at the root of the blade and maximum elongations and temperatures happened at the blade tip. While, maximum values of strains and stresses were noticed near to blade root and upper surface along the turbine blade roots. It is concluded that the temperature had an important effect on the stresses happened in the turbine blades. The Inconel 625 has better thermal properties due to low blade temperature and thermal stresses induced. Griffin \& Kumar [8] made a research on the analysis and design of gas turbine blade using Solid Work, in order to simulate the solid model of the turbine blade and ANSYS software of F.E. model and thereby applying the boundary condition. The results show that the thermal stresses are predominant in the investigation when compared with the pressure and centrifugal forces. Deformations gradually increase from root to the tip section of the turbine blade. It was noticed that the best material was Coated Haynes 188 Alloy performance better than other alloys in all features such as temperature distribution, total deformation, and induced stress. Dhamecha et al. [9] examine the failure of the gas turbine blade through structural analysis using ANSYS 16.0. Two different blade configurations have been investigated, one is the base line structure with film cooling cylindrical holes along the entire length and in another structure is, the holes along the leading edge of blade. The results demonstrate that the minimum strain at the origin section of the blade and maximum strain at the tip section, and the maximum stresses were noticed adjacent to the root section and minimum at the tip section of the turbine blade. Also, the maximum stresses are observed adjacent to the film cooling holes due to high stress concentration alongside of the holes. The current paper presents a numerical study for gas turbine rotor blades under three different values of force $(5000,10000,15000) \mathrm{N}$ when the blades fabricated of two various materials which are Aluminum Alloy and Titanium Alloy, in order to compare their behavior under load. Many parameters are obtained in to achieve the goal of this study such as total deformation, stress, strain and shear stress. The simulation of Gas turbine blades was achieved by using Solidworks 2018 whiles the numerical analysis done with ANSYS 15.

\section{METHODOLOGY}

This study presents a numerical analysis for gas turbine rotor blades under different loads with two materials Aluminum Alloy and Titanium Alloy, the simulation was done with solidworks 2018 as shown in figure 1 with 3 o blades. 


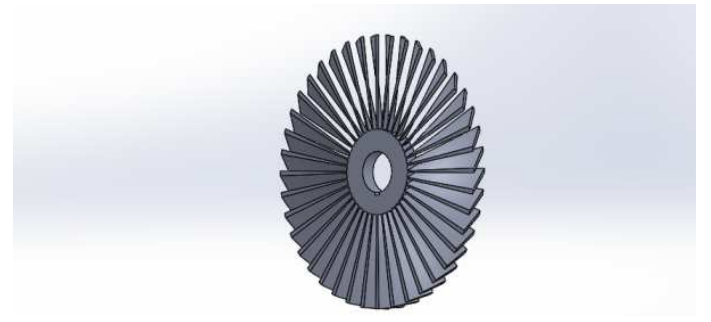

Figure 1: Gas Turbine Blades

The numerical analysis was achieved by using finite elements software ANSYS 15. The mesh process of gas turbine rotor was done with number of nodes 35731 while the number of elements was 4680 as shown in figure 2

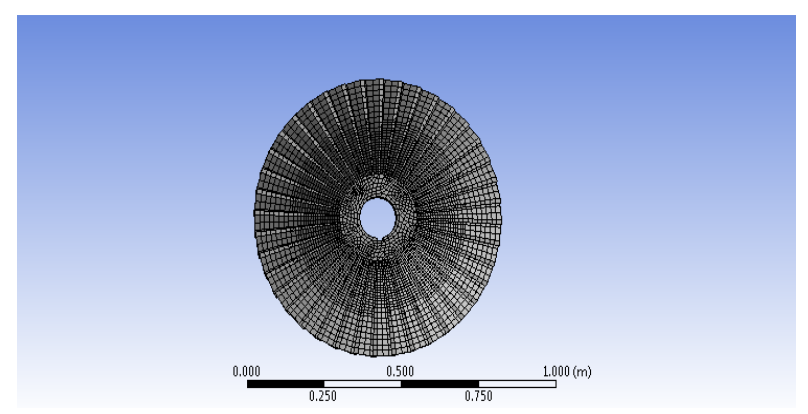

Figure 2: The Mesh of Gas Turbine Rotor Blades

Two different materials were used, which were Aluminum Alloy and Titanium Alloy to manufacture the gas turbine rotor blades and their properties listed in table. 1 below.

Table 1: The Properties of Materials

\begin{tabular}{|c|c|c|c|}
\hline Material & Density & Young Modulus & Poisson Ratio \\
\hline Aluminum Alloy & $2770 \mathrm{Kg} / \mathrm{m}^{3}$ & $7.1 \mathrm{e}^{10} \mathrm{pa}$ & 0.33 \\
\hline Titanium Alloy & $4620 \mathrm{~kg} / \mathrm{m}^{3}$ & $9.6 \mathrm{e}^{10} \mathrm{pa}$ & 0.36 \\
\hline
\end{tabular}

To understand the behavior of gas turbine rotor blades under different loads $(5000,10000,15000) \mathrm{N}$, many parameters were got like stress, strain, total deformation and shear stress.

\section{RESULTS}

The finite elements analysis software ANSYS 15 was used to obtain the numerical analysis of gas turbine rotor blades, and the results for gas turbine rotor under $(5000 \mathrm{~N})$ listed in table 2.

Table 2: Results for Load (5000) $\mathbf{N}$

\begin{tabular}{|c|c|c|c|c|c|}
\hline Materials & $\begin{array}{c}\text { Load } \\
(\mathbf{N})\end{array}$ & $\begin{array}{c}\text { Max. Total Deformation } \\
(\mathbf{m})\end{array}$ & $\begin{array}{c}\text { Max. Stress } \\
(\mathbf{p a})\end{array}$ & $\begin{array}{c}\text { Max. Strain } \\
(\mathbf{m} / \mathbf{m})\end{array}$ & $\begin{array}{c}\text { Max. Shear Stress } \\
(\mathbf{p a})\end{array}$ \\
\hline Aluminum Alloy & 5000 & 0.08275 & $2.865 \mathrm{e}^{8}$ & 0.00471 & $1.381 \mathrm{e}^{8}$ \\
\hline Titanium Alloy & 5000 & 0.061 & $2.852 \mathrm{e}^{8}$ & 0.0034 & $1.375 \mathrm{e}^{8}$ \\
\hline
\end{tabular}

The results for gas turbine rotor under $(10000 \mathrm{~N})$ listed in table 3.

Table 3: Results for Load (10000) $\mathrm{N}$

\begin{tabular}{|c|c|c|c|c|c|}
\hline Materials & $\begin{array}{c}\text { Load } \\
(\mathbf{N})\end{array}$ & $\begin{array}{c}\text { Max. Total Deformation } \\
(\mathbf{m})\end{array}$ & $\begin{array}{c}\text { Max. Stress } \\
(\mathbf{p a})\end{array}$ & $\begin{array}{c}\text { Strain } \\
(\mathbf{m} / \mathbf{m})\end{array}$ & $\begin{array}{c}\text { Max. Shear Stress } \\
(\mathbf{p a})\end{array}$ \\
\hline Aluminum Alloy & 10000 & 0.1655 & $5.73 \mathrm{e}^{8}$ & 0.00943 & $2.763 \mathrm{e}^{8}$ \\
\hline Titanium Alloy & 10000 & 0.1222 & $5.70 \mathrm{e}^{8}$ & 0.00693 & $2.751 \mathrm{e}^{8}$ \\
\hline
\end{tabular}


The results for gas turbine rotor under $(15000 \mathrm{~N})$ listed in table. 4 below

Table 4:Results for Load (15000) N

\begin{tabular}{|c|c|c|c|c|c|}
\hline Materials & $\begin{array}{c}\text { Load } \\
(\mathbf{N})\end{array}$ & $\begin{array}{c}\text { Max. Total Deformation } \\
(\mathbf{m})\end{array}$ & $\begin{array}{c}\text { Max. Stress } \\
(\mathbf{p a})\end{array}$ & $\begin{array}{c}\text { Strain } \\
(\mathbf{m} / \mathbf{m})\end{array}$ & $\begin{array}{c}\text { Max. Shear Stress } \\
(\mathbf{p a})\end{array}$ \\
\hline Aluminum Alloy & 15000 & 0.248 & $8.595 \mathrm{e}^{8}$ & 0.0141 & $4.144 \mathrm{e}^{8}$ \\
\hline Titanium Alloy & 15000 & 0.1832 & $8.556 \mathrm{e}^{8}$ & 0.01 & $4.127 \mathrm{e}^{8}$ \\
\hline
\end{tabular}

The maximum total deformation of gas turbine rotor blades made of Aluminum Alloy under (5000 N) was $(0.08275 \mathrm{~m})$ as shown in figure 3.

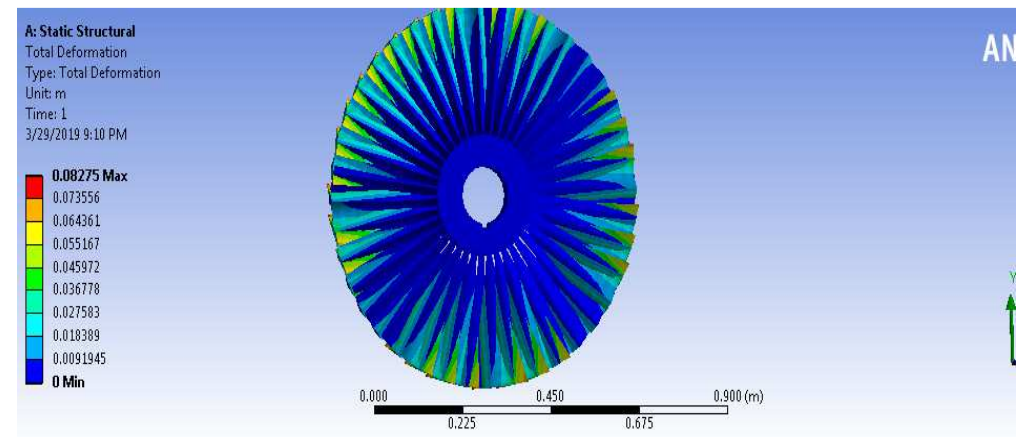

Figure 3: The Total Deformation for Gas Turbine

The maximum stress for gas turbine blades fabricated of Titanium alloy under $(10000 \mathrm{~N})$ was $\left(5.70 \mathrm{e}^{8}\right.$ pa) as shown in figure 4.

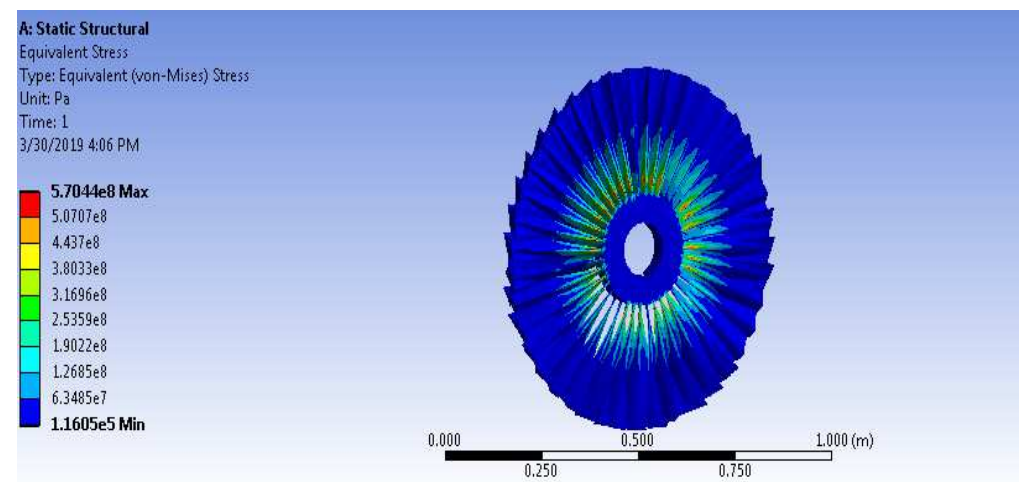

Figure 4: The Stress for Gas Turbine Blades

The maximum strain for gas turbine blades fabricated of Aluminum Alloy under $(15000 \mathrm{~N})$ was $(0.0141 \mathrm{~m} / \mathrm{m})$ as shown in figure 5.

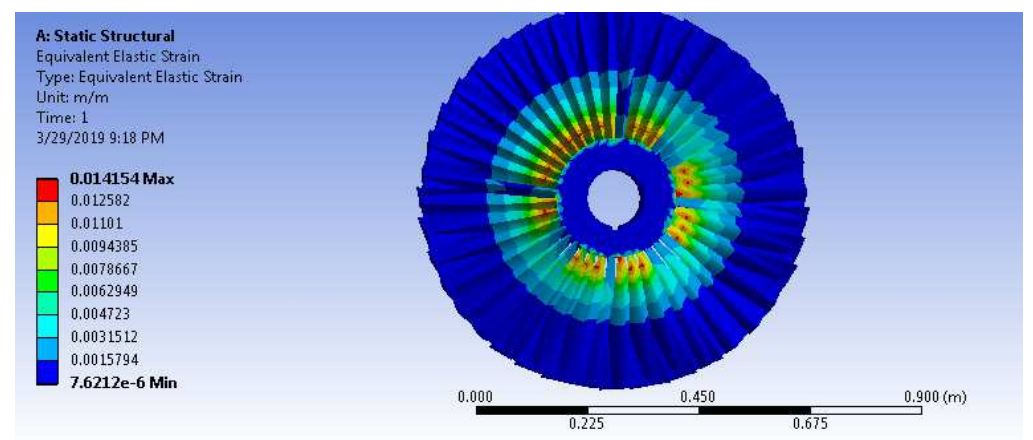

Figure 5: The Strain for Gas Turbine Blades 
The maximum shear stress for gas turbine blades fabricated of Titanium alloy under (15000N) was $\left(4.127 \mathrm{e}^{8} \mathrm{pa}\right)$ as shown in figure 6.

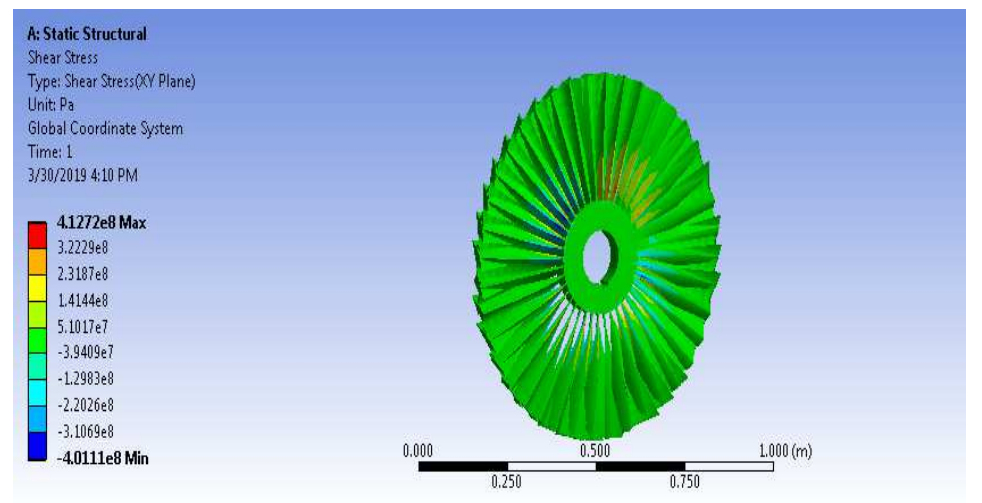

Figure 6: The Shear Stress for Gas Turbine Blades

The comparison of maximum total deformation of gas turbine rotor blades for two materials, under the three different values of loads is shown in figure 7.

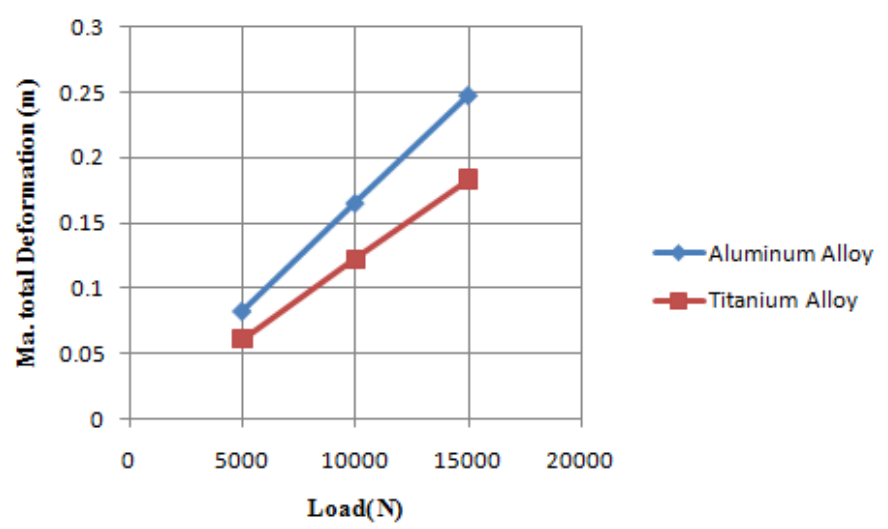

Figure 7: The Comparison of Total Deformation

The comparison of maximum stress for gas turbine rotor blades for two materials under, the three different values of loads is shown in figure 8 .

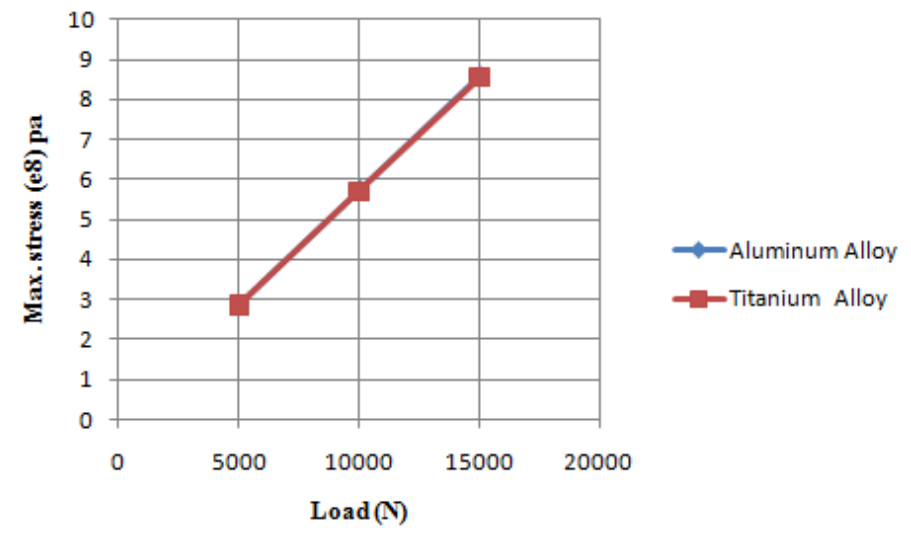

Figure 8: The Comparison of Stress

The comparison of strain for gas turbine rotor blades for two materials, under the three different values of loads is shown in figure 9. 


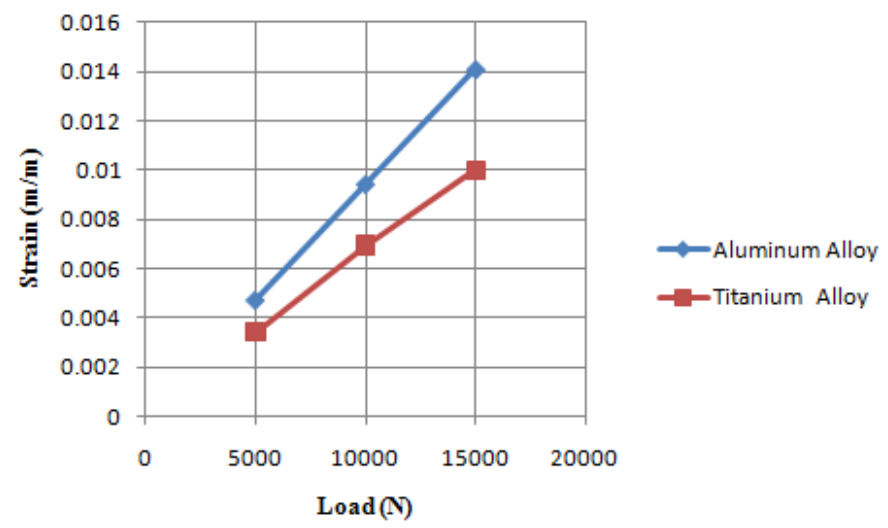

Figure 9: The Comparison of Strain

The comparison of shear stress for gas turbine rotor blades for two materials, under the three different values of loads is shown in figure 10.

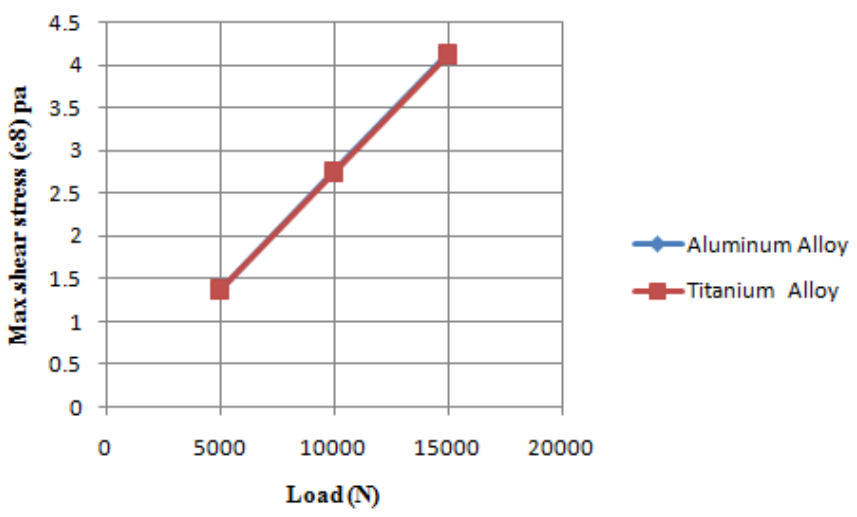

Figure 10: The Comparison of Shear Stress

\section{CONCLUSIONS}

This paper presented a numerical analysis of gas turbine blades, in order to understand their behavior under the external loads. The simulation of gas turbine blades was carried out by using solidworks 2018, while the numerical analysis was done by using ansys 15 . The results showed that by increasing the values of loads, the stress, strain, total deformation will increase. The results demonstrated that the Titanium alloy could withstand the load more than the aluminum alloy, so that it is recommended to use it in the manufacturing of gas turbine blades and to bear the high temperature. For the future works, it is recommended to use different materials with different values of loads.

\section{REFERENCES}

1. K. Harshavardhan Reddy, D. Raghurami Reddy, N. Balajiganesh. "Structural and thermal analysis of a gas turbine blade", International Journal of Engineering and Innovative Technology (IJEIT), Vol. 7, Issue-3, September 2017, Pages: 38 - 42.

2. S.Gowreesh, N.Sreenivasalu Reddy and N.V.Yogananda Murthy. "Convective heat transfer analysis of a aero gas turbine blade using ANSYS", International journal of Mechanics of solids, Vol. 4, No.1, March 2009(ppt55-62).

3. Theju V, Uday P S,PLV Gopinath Reddy, C.J. Manjunath, "Design and analysis of gas turbine blade, " International Journal of Innovative Research in Science, Engineering and Technology, ISSN:2319-8753.

4. Reddy, A. C. Low and high temperature micromechanical behavior of bn/3003 aluminum alloy nanocomposites. 
5. K Hari Brahmaiah,M lava Kumar, "Heat Transfer Analysis of Gas Turbine Blade Through Cooling holes", International Journal of Computational Engineering Research, ISSN:2250-3005.

6. Win Laihtwe, Htay Win, Nyein Aye San, "Design and Thermal Analysis of Gas Turbine Blade "International Journal of Mechanical And Production Engineering, ISSN: 2320-2092,Vol. 3, Issue-7, July 2015

7. G. Boyaraju, S. Rajasekhar, A.V Sridhar, J.Hari Narayana Rao. "Thermal Analysis Of A Gas Turbine Rotor Blade”, International Journal of Science Engineering and Advance Technology, IJSEAT, Vol. 3, Issue-12, 2015.

8. P.V.Krishnakanth, G.Narasa Raju,R D V. Prasad, R. Saisrinu. "Structural \& Thermal Analysis of Gas Turbine Blade by Using F.E.M", International Journal of Scientific Research Engineering \& Technology (IJSRET), ISSN: 2278 - 0882, Vol. 2, Issue-2, May 2013.

9. Abou-Rayan, A. M., Khalil, N. N., \& Afify, M. S. Dynamic Characteristics of Three Different Tlp's Supporting 5-Mw Wind Turbines under Multi-Directional Random and Regular Waves.

10. Griffin.T and Rajesh Kumar.B. "Analysis of Ceramic (SiC) Coated Gas Turbine Blade using ANSYS", International Journal of Recent Innovation in Engineering and Research, ISSN: 2456 - 2084, Vol. 2 Issue: 05 May- 2017.

11. Lalit Dhamecha, Shubham Gharde, Ganraj More, M.J.Naidu. "Design and Analysis of Gas Turbine Blade with Varying Pitch of Cooling Holes", International Journal of Engineering Trends and Technology (IJETT),Vol. 34, No. 8, April 2016. 
